\title{
Ciudad Universitaria, no sólo un espacio arquitectónico
}

\author{
Monserrat Mendoza Plata
}

Monserrat Mendoza Plata

mon.mendoza.p@gmail.com

Estudiante de arquitectura en el Taller Luis Barragán. Se ha dado a la tarea de, a la par de continuar con su desarrollo escolar, analizar un poco más a fondo la arquitectura con la que diariamente convivimos. Es así que logra transformar el análisis en un bosquejo con tonos azules. Incluso ha llevado a otros países su ejercicio de análisis, ampliando aún más el contexto y el objeto de estudio. También ha desarrollado y colaborado activamente en distintos proyectos de arquitectura y diseño en diferentes ámbitos desde el 2014.

7188-1090. 
"¿Y qué se siente?, ¿cómo le hiciste?", estas son preguntas frecuentes que nos hacen nuestros familiares y amigos cuando se enteran que logramos entrar a la UNAM. Recibir esta noticia, posterior a la incertidumbre por la que se pasa, es impactante. Después de todo el esfuerzo se siente tanto alivio. La pregunta que inmediatamente surge es: ¿y ahora qué? Entonces viene la etapa de asimilación y de preparación; hasta que por fin llega el día de comenzar esta aventura. La pregunta antes planteada se responde por sí misma cuando empezamos a vivir la gran experiencia de ser estudiante de la máxima casa de estudios.

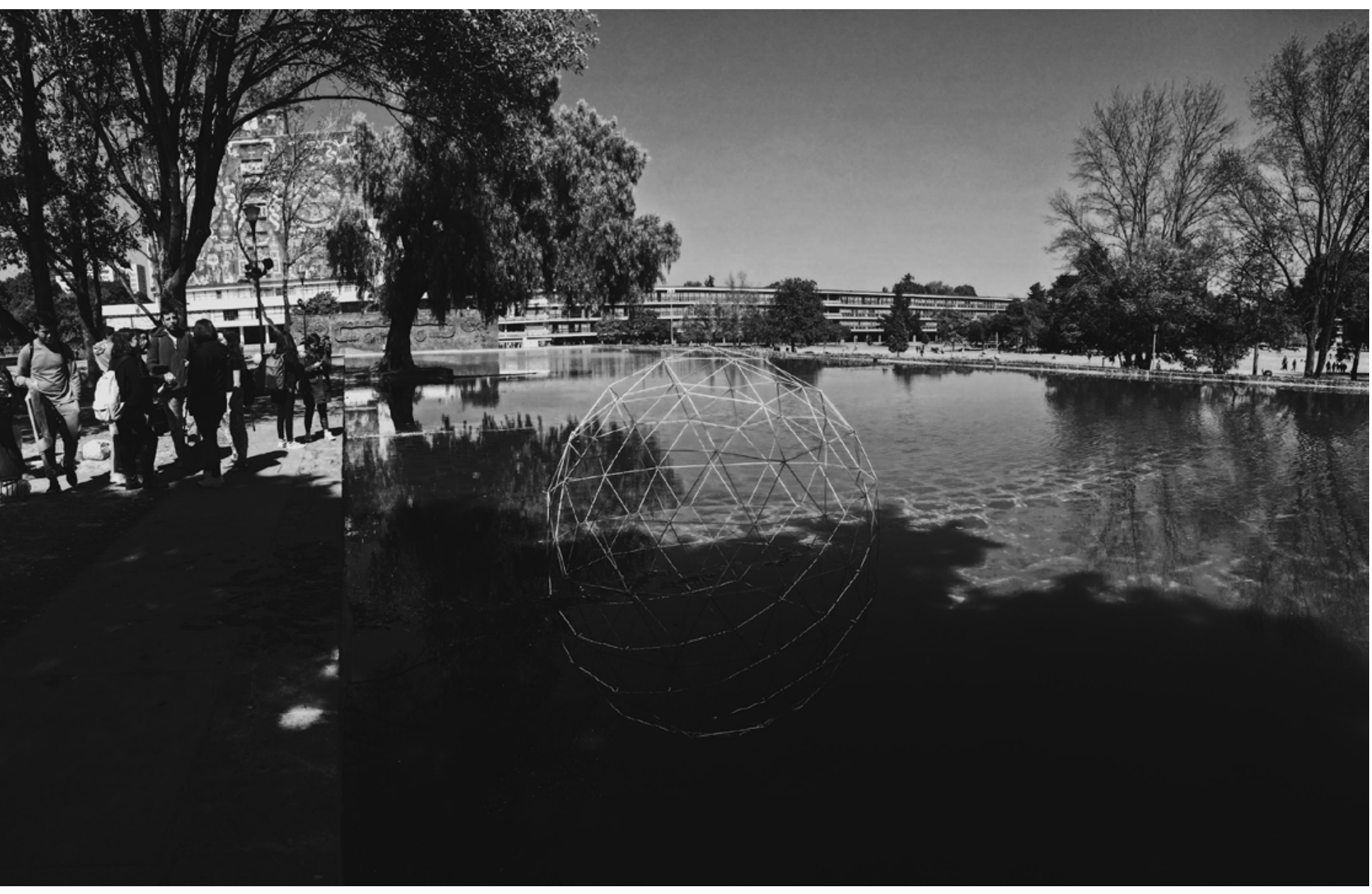




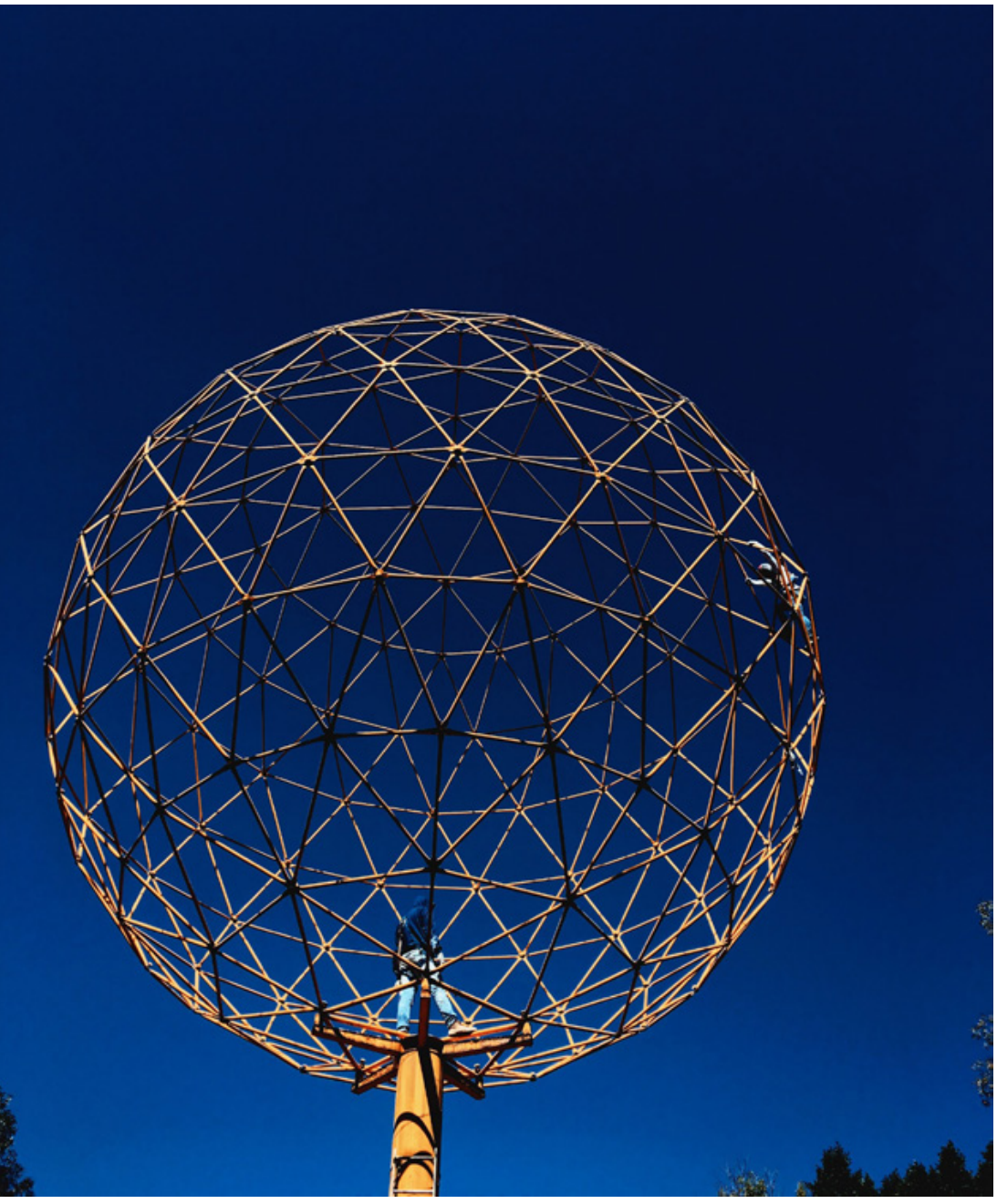

La experiencia universitaria se conforma de múltiples factores que la hacen única y distinta para cada uno. En lo personal, algunas de las cosas que me siguen maravillando son el gran número de personas nuevas que he conocido, lo mucho que se puede aprender (literalmente de todo), el descubrir profesores que me ayudan a identificar en qué soy buena y a potencializar esas virtudes; además de encontrar lo que me apasiona y poder cultivarlo. Pero la más importante de todas: nunca me cansaré de pertenecer a esta gran familia, porque la Universidad se vuelve tu segunda casa.

Pasan los años tan rápido que no te das cuenta en qué momento sucedió todo y de pronto tienes que decidir qué carrera estudiar. Para los egresados del bachillerato de la UNAM hay dos opciones: hacer examen o utilizar el pase reglamentado; cualquiera de las dos opciones que se elija representa todo un reto, puesto que elegir qué estudiar es una decisión que marcara para siempre nuestra vida y definirá la forma en que se conducirá el resto de la misma.

Así que, después de pensarlo mucho, decidí estudiar arquitectura. La incertidumbre era excesiva, porque nunca se sabe qué esperar, mucho menos cuando te han dicho un sinfín de veces que esa carrera, en particular, es sumamente difícil y exigente. Con oídos sordos a estos comentarios decidí intentarlo y los resultados han sido asombrosos. No puedo negar que ha sido desgastante, difícil y exigente, pero todo vale la pena cuando se hace un recuento de los conocimientos adquiridos, las experiencias vividas y las amistades forjadas. Sí, es cierto que hay días (más de los que esperaba) que no duermo, que toda mi casa se convierte en un almacén de maquetas. Incluso mi vida social va disminuyendo semestre con semestre, pero, por otro lado, he vivido cosas increíbles, como conocer lugares de la república mexicana que antes no conocía, cursar materias que nunca pensé que existirían, conocer a personas increíbles y, después de un arduo trabajo, ser felicitada por algún maestro debido a un buen desempeño.

Sumado a todo esto, es importante mencionar que, además de todas las ventajas que la Facultad de Arquitectura y la UNAM nos ofrecen, dicha institución está alojada en uno de los espacios más asombrosos de la Ciudad de México. Es incomparable ver el amanecer desde los pasillos de la facultad, tomar un 
respiro en las islas mientras admiras el atardecer, andar en bicicleta con tus amigos, además de poder analizar y admirar todas las obras arquitectónicas ahí albergadas.

Inaugurada oficialmente en 1954, Ciudad Universitaria actualmente es la casa de más de 205 mil 648 estudiantes, pero ha visto pasar, a través del tiempo, innumerables generaciones. Y así viaja en el tiempo para hacerse un ente atemporal que conserva su belleza y esplendor.

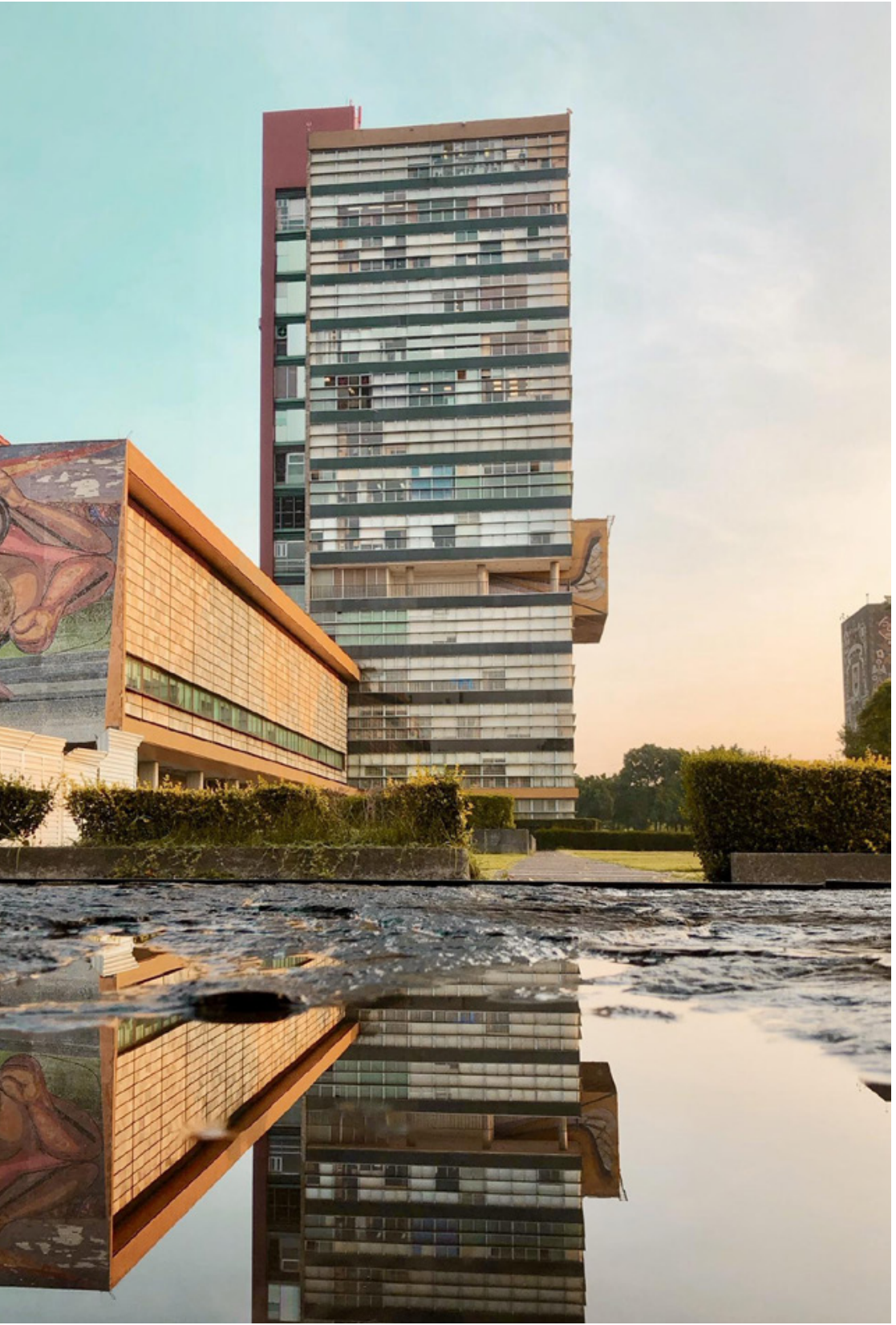

Después de haber leído, estudiado, contemplado e intentado comprender un poco más a fondo qué es el espacio arquitectónico, puedo concluir que éste va mucho más allá de la simple respuesta a la funcionalidad o la edificación que pretende resolver. Envuelve, más de lo que uno se puede imaginar, un ámbito social y cultural. El campus central de Ciudad Universitaria es un claro ejemplo de cómo todos estos factores (sociales, culturales, temporales, artísticos y estéticos) se fusionan para lograr una composición estética y funcional, un espacio arquitectónico lleno de belleza y armonía. Lo anterior no sólo se observa en su fachada sino en todos sus edificios, lo que resulta en una coherencia entre el interior y exterior. Es necesario entender que cuando se habla de arquitectura, ésta envuelve más que un espacio.

Así que, si nos detenemos a contemplar minuciosamente cada construcción, podremos comprender que nos cuenta una historia, que incluso podemos escucharla por las voces que se quedaron plasmadas en sus paredes y pasillos. Vemos así que Ciudad Universitaria es un espacio arquitectónico digno de admiración.

Y entonces también entendemos que Ciudad Universitaria no es sólo un espacio arquitectónico, sino que va mucho más allá. Deja de ser un conjunto de edificaciones para volverse el hogar de muchos estudiantes, se convierte en el 
testigo de muchas historias, éxitos y amistades que duran para siempre. Considero que ésta es una experiencia que marcará las vidas de muchas generaciones.

\section{Cómo citar este artículo}

- Mendoza Plata, Monserrat (2018). Ciudad Universitaria, no sólo un espacio arquitectónico. Revista Digital Universitaria (RDU). Vol. 19, núm. 4 julio-agosto. DOI: http:// doi.org/10.22201/codeic.16076079e.2018.v19n4.a6. 